\title{
Application of BIM technology in the construction of ChangKe 6\# building
}

\author{
Yan Cui ${ }^{1, *}$, Yingyu Tai ${ }^{2}$ \\ ${ }^{1}$ College of Bridge Engineering, Jilin Communications Polytechnic, 130012, Changchun City, Jilin Province, The People's Republic of \\ China \\ ${ }^{2}$ Changchun Sci-Tech University, College of Civil Engineering and Architecture, 130000 Changchun City, Jilin Province, The People's \\ Republic of China
}

\begin{abstract}
The construction industry complies with the development needs of the times, constantly explores new ways of transformation and upgrading, and the emergence of BIM Technology leads a new route for the future development of the construction industry. BIM Technology is widely used in the construction process of the $6 \#$ building Changke, which effectively improves the management efficiency in the whole construction process. In this project, first of all, the relevant practical software is used to prepare the project budget document, the schedule plan, the material procurement plan are prepared in combination with the quantities, the situation awareness effect of the construction site is presented in combination with BIM site management and other software, and the all-weather information management of the whole site and all areas is realized.
\end{abstract}

\section{Background}

BIM is a kind of new technology, which is closely related to the progress, cost and other information of the building through the computer, and presented in threedimensional form. BIM Technology is not only a new technology, but also the result of interactive development with the latest technology in the construction industry and related industries, relying on the development of computer-aided design to threedimensional ${ }^{[1]}$. The emergence of BIM Technology leads a new route for the future development of the construction industry. At the same time, BIM is not only a technology, but also an integrated complex of building informatization. BIM can be compatible with project progress, cost, quality, safety and other information in building technology ${ }^{[2]}$. BIM can be integrated with AR (augmented reality), VR (virtual reality), artificial intelligence, UAV, $5 \mathrm{~g}$ and other high-tech industries to present the project in a three-dimensional and dynamic way The purpose of the whole picture is helpful to the basic development of the construction industry ${ }^{[3-7]}$.

\section{Project introduction}

\subsection{Project introduction}

Changke 6\# building is located in the campus of Changchun Sci-Tech University, Shuangyang District, Changchun City, Jilin Province. The project overview is shown in the table below.
Table 1. Basic information of $6 \#$ building

\begin{tabular}{|l|l|}
\hline Name & ChangKe 6\#building \\
\hline Architectural uses & Office building \\
\hline Building storey & 8 \\
\hline Storey height & $3 \mathrm{~m}$ \\
\hline Building height & $23.7 \mathrm{~m}$ \\
\hline Design service life & 50 years \\
\hline Seismic fortification intensity & 7 \\
\hline Fire resistance rating & second level \\
\hline Construction area & $5624.62 \mathrm{~m}^{2}$ \\
\hline Structural style & $\begin{array}{l}\text { reinforced concrete } \\
\text { structure }\end{array}$ \\
\hline
\end{tabular}

\subsection{Analysis of problems in the project}

The problems faced by the construction of the building are as follows.

Plan and change management: Because the project construction is in the summer rainy season for three months, the construction stoppage and water accumulation after the rain may occur. From the preparation of the schedule to the site layout, all kinds of random accidental factors need to be considered, especially the mobilization of materials and the implementation of the schedule are more important.

Site management issues: Construction site management is dynamic, especially the implementation of schedule, coordination of various types of work,

\footnotetext{
*Corresponding author: 924804381@qq.com
} 
control of construction links, etc. It is easy to lead to unclear implementation of project schedule, lack of onsite situation awareness ability of management personnel, and greater power dependence of project management than fact awareness.

Project implementation effect: Project construction is a long-term activity. Before the construction of a project, few people can predict the final effect of the project and the final impact of related effects.

\section{Countermeasures to solve related problems by BIM Technology}

\subsection{Resolve project planning and reduce change issues}

The project applies the progress planning software, prepares the project network plan, and comprehensively presents the whole process of the progress plan in combination with the BIM construction effect chart. The planned duration of the project is 162 days.

The project plan of this project mainly involves the allocation of resources. In the construction stage of the project, a large number of materials such as steel bars, cement, sand are required to be purchased. However, with the arrival of the summer rainy season, the consumption of materials is in a random state under the influence of weather and force majeure. Therefore, the material consumption plan adopts mathematical model analysis to assist decision-making. The specific analysis and deployment forms are as follows:

(1) Construction deployment decision under special circumstances: it is known that June to August in Changchun area is a period of heavy rainfall throughout the year, so it can be assumed that this period is a construction period of discontinuous rainy season. During this period, irregular precipitation has a great impact on the implementation of construction progress, especially the mobilization of consumable materials and equipment. When planning the application of materials, it can be assumed that the consumption of non revolving materials is a random variable. For every certain amount of materials consumed, the construction company can obtain the project payment of $\mathrm{H}$ yuan. If the materials are not consumed on the same day, the resulting cost loss of material storage and idling is $\mathrm{K}$ yuan. According to the normal schedule, the probability of daily material demand $\mathrm{R}$ is $\mathrm{P}(\mathrm{R})$, then how much material consumption per day is appropriate in rainy season?

(2) Deploy decision-making ideas and create BIM 3D site layout scheme. In the construction stage of the project, the construction site planning software is used to draw the three-dimensional layout of the BIM site, and the comprehensive deployment is as follows:

a. Cross operation deployment of material yard and site. The mathematical model is used to solve the problem of the number of incoming and exiting sites under special circumstances. However, the layout of the site, the implementation of the project plan, and the management activities to avoid losses and claims are all dynamic.
The ring access route (as shown in Fig. 1 and Fig. 2) is set for the project site. The material access is shown by the arrow in the figure. After the material transport vehicles enter the site and unload, they drive out from the other side door by the ring road, ensuring the smoothness of material transport in normal times and special periods. The same method is adopted for the construction vehicles of concrete vehicles to ensure the continuity of mass concrete pouring, avoid the congestion of vehicles and materials in the site, and affect the construction period. All vehicles in and out of the site can choose various routes as soon as they stop, which is also convenient for the managers to make flexible decisions.

The material stacking and processing area are located within the coverage of the site tower crane, and they are adjacent to each other, so as to facilitate the hoisting and transfer of materials. During the main construction, the cantilever unloading platform is set, and the platform and material processing are not in the same direction, which ensures the cross operation of unloading and work below, and further guarantees the safety of the construction site.

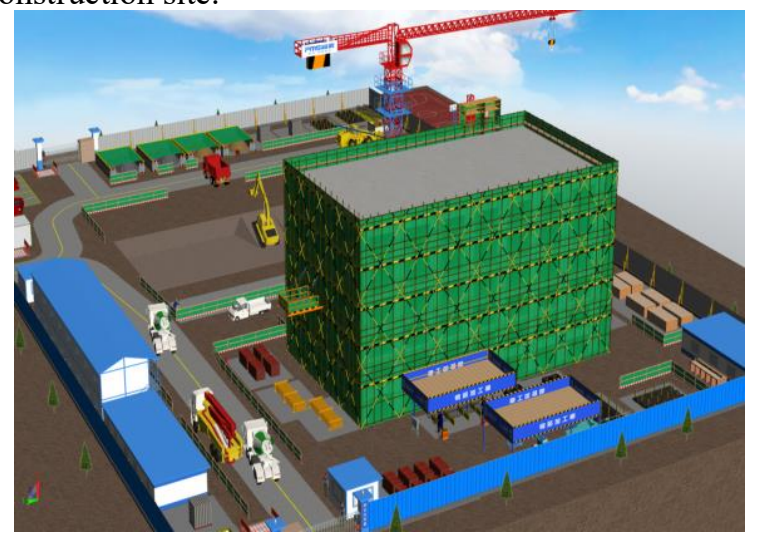

Fig. 1. General 3D view of site layout

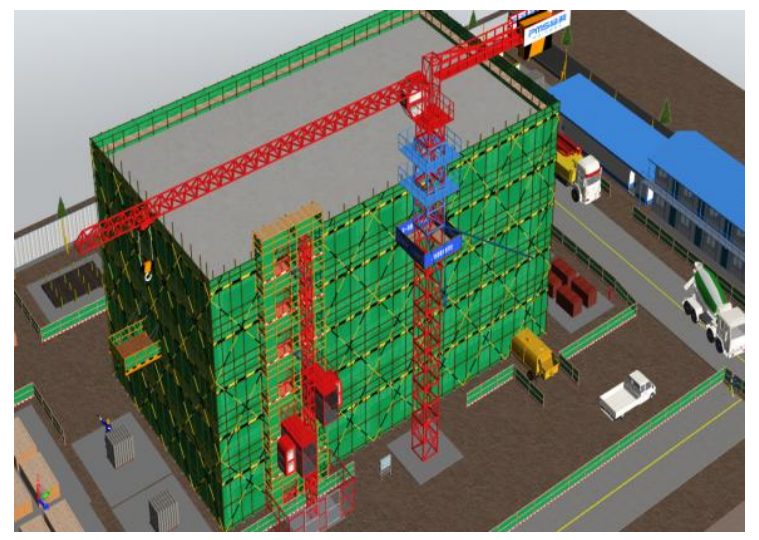

Fig. 2. Layout of construction area

b. Earthwork transportation shall be considered for site deployment, and excavation shall be carried out in layers and areas, that is, excavation is carried out immediately. The excavation position of foundation pit shall be kept at a certain distance from the site exit. When the vehicle passes this distance, it shall turn naturally to ensure that the vehicle can shake off the 
scattered soil in the site without causing pollution outside the site. Detailed operation is shown below.

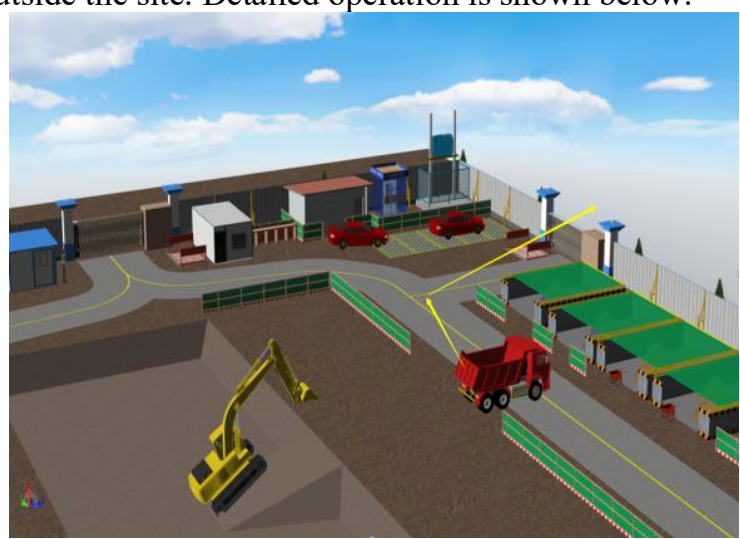

Fig.3. Layered excavation and excavated Road

The application of BIM Technology to draw threedimensional site layout can effectively solve the problem of project plan implementation and consumables mobilization in the period of frequent rainfall, among which the reasonable planning of roads and the accurate setting of import and export positions are particularly important. In addition, during the rainy season, the dewatering and drainage of the construction site is also an important aspect affecting the planning and change. In the process of three-dimensional site layout of the project, the problem of low terrain in the Lingxia area of Shuangyang District shall be reasonably considered, and the site elevation shall be designed in a scientific way to solve the drainage problem. After the rain falls, there will be no ponding, avoiding the occurrence of pumping delay $^{[2]}$.

\subsection{BIM4D simulation technology to solve site management problems}

The management of the construction site is mainly to plan and implement the project schedule reasonably under the premise of meeting the basic requirements of quality and safety and under the condition of well controlling the project cost[3]. The 4D simulation process of BIM construction for temporary facilities and construction main body is realized by software. The main work is accomplished in three aspects.

Virtual construction of temporary facilities: As shown in Figure 4, the construction site is divided into construction area, material storage yard, processing area, office area and rest area from the outside to the inside, the road and site are hardened, the access point of power source is selected and the temporary pipeline box valve is arranged.

Main construction: As shown in Figure 5, the construction sequence of construction works is from underground to ground, from main body to masonry. The first floor is reserved for wall masonry, from bottom to top, and the external decoration is from top to bottom. Internal and external decoration and water and electricity installation can be carried out simultaneously. Finally, all the work of the first floor and the closing work of the whole project are completed. The orderly implementation of the project is conducive to the project schedule management and the cost control of the project.

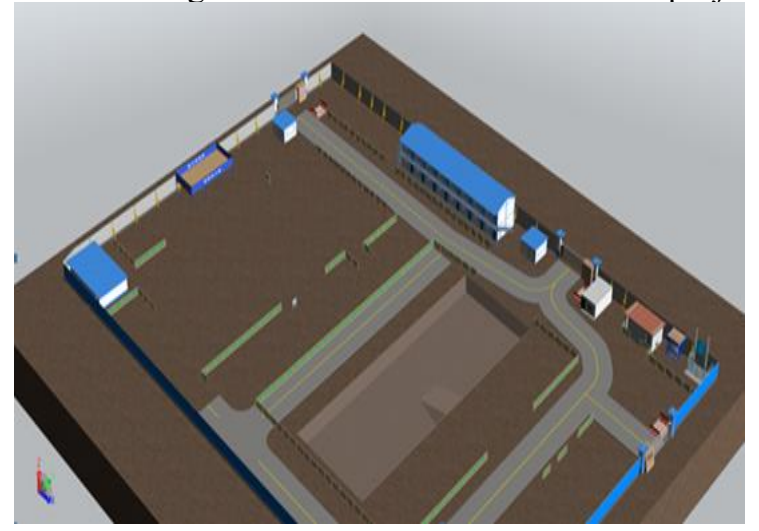

Fig.4. Simulation effect of temporary facilities

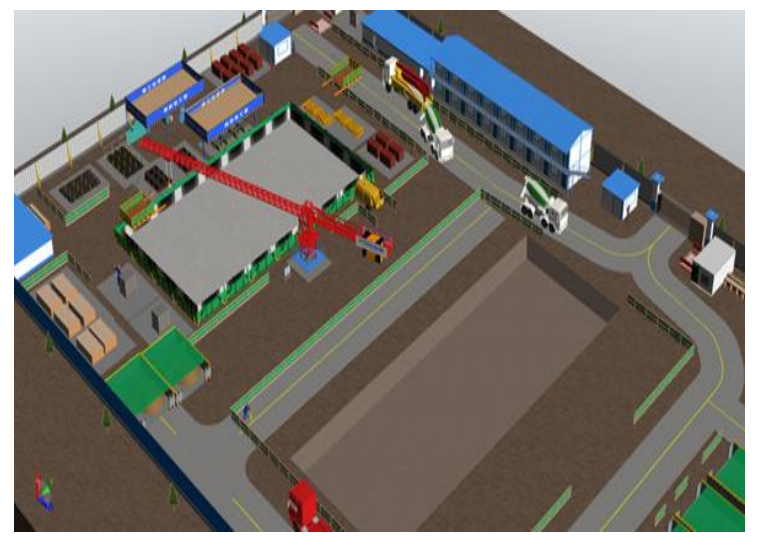

Fig.5. Construction simulation effect

Situational awareness: In the process of dynamic management of construction site, BIM construction simulation process helps to improve the project management level and realize comprehensive site management; at the same time, site situation awareness is not only the sense of existence of construction personnel, but also an important part of safety management. Meanwhile, site situation is conducive to the control of construction quality. This process presents safety and quality in three-dimensional form through BIM Technology The control point is conducive to the management of site safety and quality, as well as the site command and scheduling, and the implementation of project management. The effect example is shown in Figure 8 . The personnel are located under the temporary unloading platform. Attention should be paid to the safety of personnel during cross operation and non cross operation, as well as the prevention of material damage. 


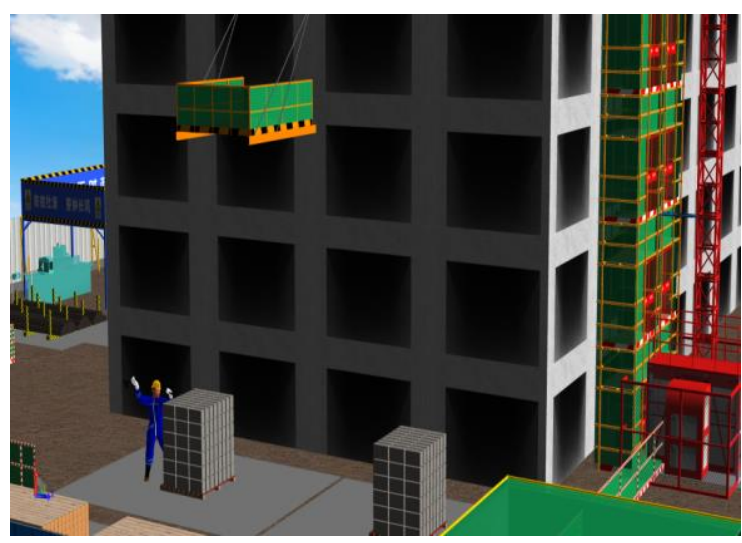

Fig.6. Site situation awareness of construction personnel simulated

\subsection{BIM Technology to solve the problem of project implementation effect}

Project implementation is not only a quality control issue, but also the final effect style of the project, which also determines the success and failure of the project. In this project, Revit 3D modeling software and VDP decoration effect roaming software [4] are applied, and the project effect is expected to be adjusted during the construction process. The effect seen through effect roaming is used as a reference for project management. The specific design scheme is shown in the figure below.

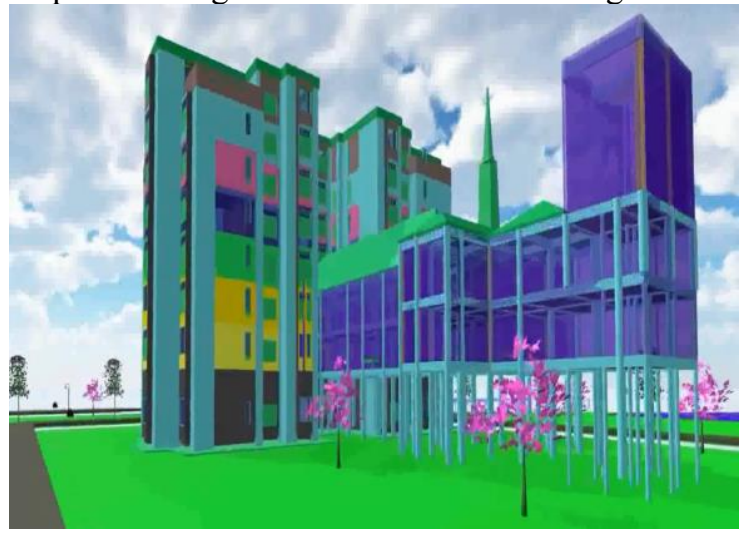

Fig.7. Project appearance reference renderings

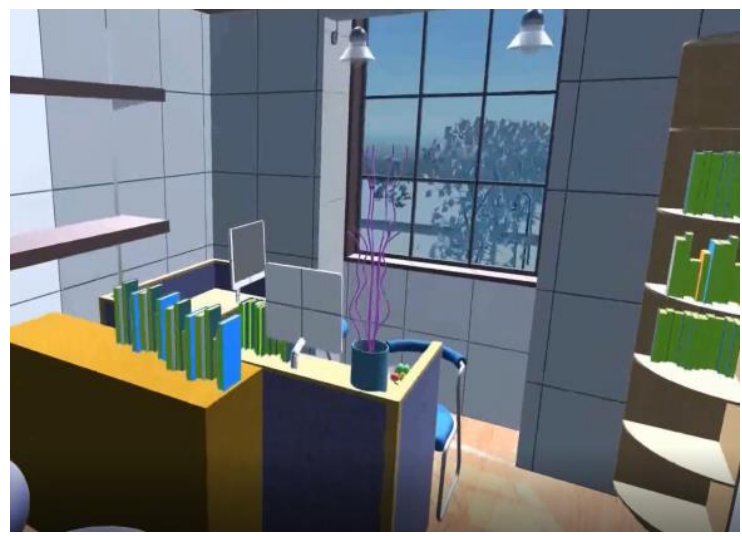

Fig.8. Decoration effect drawing of Management Office

\section{Conclusion}

In the construction stage of the project, BIM Technology is comprehensively applied, practical measurement and pricing software is comprehensively applied to provide basic data, and Pin Ming software is used to prepare site planning documents, which well realizes the transformation from two-dimensional to threedimensional. Meanwhile, Revit and VDP software are used to draw three-dimensional effect and realize model roaming, which greatly improves the management efficiency of the construction unit and effectively assists Construction effect of the construction unit. At the same time, as a school construction project, it also provides a platform and model for students to learn from. More importantly, this project provides a reference case for the follow-up related similar projects, and plays a demonstration role for the follow-up projects.

\section{References}

1. ZHOU Chun-bo. Application of BIM Technology in construction[J]. Journal of Qingdao University of science and technology, 01(2013)

2. Ki Pyung Kim,Kenneth Sungho Park. Housing information modelling for BIM-embedded housing refurbishment[J]. Journal of Facilities Management, 16(2018)

3. Botao Zhong,Chen Gan,Hanbin Luo,Xuejiao Xing. Ontology-based framework for building environmental monitoring and compliance checking under BIM environment[J]. Building and Environment, (2018)

4. Meng Li,Hongliang Yu,Ping Liu. An automated safety risk recognition mechanism for underground construction at the pre-construction stage based on BIM[J]. Automation in Construction, (2018)

5. Shahryar Habibi, Esther Adhiambo Obonyo, Ali M. Memari. Design and development of energy efficient re-roofing solutions[J]. Renewable Energy,(2020)

6. Xinzheng Lu, Zhebiao Yang, Zhen Xu. Scenario simulation of indoor post-earthquake fire rescue based on building information model and virtual reality[J]. Advances in Engineering Software,(2020)

7. Ahmed Hamieh, Aicha Ben Makhlouf, Borhen Louhichi. A BIM-based method to plan indoor paths[J]. Automation in Construction,(2020) 